\title{
EchoGéo
}

48 | 2019

Illegal cannabis cultivation in the world

\section{Marijuana et haschich, regards sur le cannabis}

Jean-Louis Chaléard

\section{(2) OpenEdition}

Journals

Édition électronique

URL : https://journals.openedition.org/echogeo/17588

DOI : 10.4000/echogeo. 17588

ISSN : 1963-1197

\section{Éditeur}

Pôle de recherche pour l'organisation et la diffusion de l'information géographique (CNRS UMR 8586)

Référence électronique

Jean-Louis Chaléard, " Marijuana et haschich, regards sur le cannabis », EchoGéo [En ligne], 48 | 2019, mis en ligne le 13 juillet 2019, consulté le 31 juillet 2021. URL : http://journals.openedition.org/ echogeo/17588; DOI : https://doi.org/10.4000/echogeo.17588

Ce document a été généré automatiquement le 31 juillet 2021.

EchoGéo est mis à disposition selon les termes de la licence Creative Commons Attribution - Pas d'Utilisation Commerciale - Pas de Modification 4.0 International (CC BY-NC-ND) 


\title{
Marijuana et haschich, regards sur le cannabis
}

\author{
Jean-Louis Chaléard
}

1 La présente livraison d'Échogéo est spéciale en ce sens qu'elle est très largement consacrée à un thème unique, la production de cannabis, et que les articles sont rédigés en anglais. Notre revue est a priori francophone mais nous ne publions pas que des textes en français. Surtout, les recherches et l'essentiel de la production scientifique sur le cannabis se font largement en anglais. C'est pourquoi nous avons décidé de construire un dossier de la rubrique Sur le Champ intégralement dans cette langue. Seule la rubrique Sur l'Écrit reste en français dans ce numéro.

Dans son introduction, Pierre-Arnaud Chouvy, qui a dirigé le dossier sur la production de cannabis dans le monde, souligne la relative faiblesse des publications scientifiques, notamment des géographes, sur ce sujet. Cette situation est à certains égards paradoxale, puisque le cannabis est la culture illicite la plus courante dans le monde. C'est cette lacune que le dossier contribue à combler.

3 Les huit articles du dossier, s'ils ne prétendent pas fournir une vue exhaustive de la situation, offrent néanmoins un large panorama de la production, à la fois dans des pays du Nord (États-Unis, Europe) et des pays du Sud, africains ou asiatiques, des pays où domine la consommation sous forme « d'herbe » (feuilles, fleurs, tiges séchées), plus connue sous son appellation d'origine mexicaine de marijuana, très répandue aux États-Unis, et la production de résine (haschich), plus consommée dans des pays comme la France, l'Espagne, en provenance notamment du Maroc. Ces textes permettent d'appréhender la diversité des situations, des conditions de production et des trajectoires productives rendant les généralisations délicates. Ainsi, contrairement à ce qu'on présente souvent, la production n'est pas seulement le fait de paysans pauvres du Sud (comme l'importance des petits producteurs autoconsommateurs nordaméricains et européens ou le développement récent de grandes sociétés productrices le prouvent); elle ne prospère pas seulement dans les pays en guerre... Mais des points communs se dégagent aussi, beaucoup de zones productrices étant marquées par une relative ancienneté de la production et de la consommation (plusieurs siècles), par des 
évolutions récentes majeures liées notamment à l'expansion de la culture et à la croissance de la demande, etc.

4 Les textes traitent de vastes ensembles, à l'origine d'utiles mises au point à l'échelle globale ou continentale, ou bien étudient minutieusement des cas particuliers qui permettent d'approfondir les questions. Le premier article de P.-A. Chouvy s'intéresse aux héritages, aux tendances actuelles et aux défis de la production de cannabis dans le monde. L'auteur relève que les données sont souvent limitées et peu fiables, ce qui pose problème pour analyser les enjeux actuels de la production, dans un contexte d'évolution rapide de l'activité et de la législation. Les trois articles suivant abordent le sujet en Afrique. C. Duvall distingue quatre phases dans l'histoire du cannabis sur ce continent. L'ancienneté de la culture permet de comprendre l'étendue des savoirs et l'éventail des variétés cultivées actuellement, alors que l'autorisation puis l'interdiction de la culture par les autorités coloniales ont permis dans les faits son développement, la rendant au XX⿳亠े siècle très attrayante pour les petits producteurs. Il souligne enfin que la légalisation actuelle de la culture dans plusieurs pays ne change pas les relations qui ont permis au Nord de tirer profit de la production réalisée par les agriculteurs africains. Les deux articles suivants complètent et précisent le précédent. J. Bloomer analyse le contexte de la production de cannabis au Lesotho, insistant sur son ancienneté et son rôle dans le cadre d'une stratégie de subsistance des petits producteurs. Il s'interroge sur les conséquences de l'annonce récente par le gouvernement d'une production sous licence à objectif médical. A. Laudati montre que la production de cannabis au Congo, contrairement à ce qui est souvent affirmé, n'est pas une cause de l'insécurité qui règne dans le pays mais plutôt une réponse à cette insécurité. L'interdiction du commerce du cannabis, son illégalité, façonnent les termes du commerce plus que l'inverse. J. Bradford et D. Mansfield, avec l'Afghanistan, nous font changer de continent. Le pays est célèbre pour sa production d'opium. Les auteurs relèvent qu'à côté existe une production ancienne de cannabis, composante significative de l'économie et de la culture afghanes. La hausse de la demande de haschich à partir des années 1960 a aidé à forger des réseaux mondiaux, le commerce du cannabis s'étant transformé en réponse à des facteurs aussi bien locaux, que nationaux et mondiaux. S'intéressant au cas d'un pays du Nord, N. Johnson essaie de voir comment les États-Unis sont devenus l'un des premiers pays producteurs de cannabis du monde à la fin du XX⿳亠丷⿵冂丶 et au XXI ̀̀ siècles. Il montre les processus qui ont amené la généralisation de la culture dans le pays, à partir de l'examen du cas de trois régions (Centre-Ouest, Sud et Ouest) aux trajectoires spécifiques, et comment ces évolutions aident à comprendre ce qui pousse actuellement certains États à légaliser la culture après quatre-vingts ans d'interdiction. La production de l'Europe n'a pas la même importance que celle des États-Unis, mais elle est en croissance depuis les années 1960-1970. M. Gandilhon, N. Lalam et D. Weinberger analysent cette évolution et les changements de structure qui vont avec: les acteurs sont nombreux et variés, les organisations maffieuses dominant le marché; mais les petits producteurs, dont la culture est basée sur la convivialité, représentent une dimension persistante de la production. Le dernier article de P.-A. Chouvy clôt le numéro, en même temps qu'il apporte des éléments sur les dynamiques spatiales passées et actuelles. S'appuyant sur des cas concrets (Maroc, Afghanistan, nord-est de l'Inde, Birmanie, États-Unis) l'auteur distingue trois scenarii principaux qui rendent compte d'une production de drogue à grande échelle : celui d'une guerre inefficace contre les drogues, celui d'une tolérance pour divers motifs, celui d'un État militairement contesté. La guerre contre la drogue 
paraît vouée à l'échec, remettant en cause implicitement l'illégalité de cette pratique. L'article renvoie à des interrogations actuelles posées dans tout le numéro, qui concernent la drogue mais vont aussi au-delà : relations entre l'illégal et l'illicite chez des populations cultivant de longue date le cannabis et à qui on l'interdit; question de plus en plus prégnante de la légalisation de la consommation à des fins médicales ou non, et dont les conséquences risquent d'être très importantes sur les pays producteurs du tiers monde...

Dans ce numéro en anglais sur le cannabis, la rubrique Sur l'écrit fait exception, restant dans son format et ses thématiques habituels. Serge Weber interviewe J.-B. Maudet, romancier et géographe (ou géographe et romancier ?), à propos de la parution de son dernier livre Matador Yankee qui met en scène un personnage né à la frontière entre deux mondes, pas tout à fait torero ni complètement cowboy. L'interview est l'occasion, au-delà de l'histoire du personnage, de s'interroger sur la frontière entre le Mexique et les États-Unis, immense et multidimensionnelle, sur les relations entre corrida et rodéo, l'auteur étant spécialiste des jeux taurins. Les notations géographiques sont nombreuses : logique spatiale des arènes, rôle de la communauté portugaise immigrée dans le monde de l'élevage taurin aux États-Unis, etc. Toutefois J.-B Maudet souligne que son ouvrage se démarque totalement d'un roman historique ou géographique, même si la bonne connaissance de la région lui a permis de se libérer de tout volet documentaire au moment de l'écriture. C'est pourquoi, au-delà des notations géographique, l'interview nous introduit dans une réflexion sur l'apport des écrivains nord-américains (comme Carver et Hemingway) et surtout du cinéma. Pour un autre visage de l'Ouest américain et des relations États-Unis Mexique que celui aperçu à travers le cannabis... 